\title{
LA EDUCACIÓN, Y LA EDUCACIÓN EN DERECHOS HUMANOS UN COMPROMISO POLÍTICO Y SOCIAL
}

Toda herramienta o mecanismo que busque garantizar a las niñas y los niños su formación de manera integral, debe fortalecer las condiciones que hagan posible la vivencia de los Derechos Humanos.

RESUMEN:

El siguiente artículo, muestra la puesta en marcha de las políticas nacionales e institucionales en Educación en Derechos Humanos, que tienen como fundamento la formación y protección de los derechos de los niños, niñas y jóvenes; lo cual pretende evitar cualquier forma de discriminación que pueda afectar la integridad de los mismos y, lograr la vivencia de los Derechos Humanos para la vida digna y el desarrollo en sociedad. Para esto se han tenido en cuenta las políticas nacionales e internacionales en derechos humanos, la profesionalización docente y la capacitación de los profesionales en educación, quienes elaboran los instrumentos comportamentales y planes educativos y; mostrando la importancia de invertir en Educación de los Derechos Humanos no solo en la educación básica sino en la profesional.

La importancia de la educación en derechos humanos radica en que es el motor de progreso en una sociedad, por eso la necesidad de inversión para su conocimiento y su vivencia, su objetivo es dar a conocer las normas y jurisprudencia nacional e internacional; fomentar la protección y promoción, en el quehacer educativo, para que su aprendizaje y aplicación sea coherente con los derechos humanos. 
Palabras Claves: Educación, Educación en Derechos Humanos, Manual de convivencia.

ABSTRACT:

The following article shows the implementation of national and institutional policies Human Rights Education, which has as basis the training and protection of children and young people, avoiding any form of discrimination that may affect the integrity of themselves and, ensure the survival of human rights for decent living and development in society, taking into account national and international policies and the professionalization of teachers to the development of behavioral and educational planning tools, showing the importance of investing in Education Human Rights not only basic education also in the superior education.

The importance of human rights education is in that is the engine of progress in society, why the need for investment for their knowledge and their experience, their aim is to know the rules and case law nationally and internationally; fostering the protection and promotion, in the educational task, so that your learning and application is consistent with human rights.

Key Words: Education, Human Rights Education, handbook of coexistence.

INTRODUCCIÓN:

La educación y la educación en Derechos Humanos están ligadas intrínsecamente, ya que la finalidad última de la educación, es educar al individuo en un ambiente sano en donde se vivencien los Derechos Humanos, siendo éste el camino más próximo para tomar 
conciencia del ser en sociedad y la transformación de la realidad en la construcción de la paz.

Desde la firma de la Declaración Universal de los Derechos Humanos, se inician los procesos educativos en busca de promover la dignidad humana. El derecho a la educación muestra un avance significativo desde la puesta en marcha de la declaración que busca garantizar este derecho, así la educación pasa de ser potestad única de la iglesia a ser pública y luego laica, con el fin de respetar el derecho a la libertad de cultos y el libre desarrollo de la personalidad.

Los instrumentos y organizaciones internacionales como: el Pacto Internacional de los Derechos Económicos, Sociales y Culturales, el Protocolo Adicional a la Convención Americana sobre Derechos Humanos en materia de Derechos Económicos, Sociales y Culturales, la declaración de los derechos de los Niños, la organización de los Derechos Humanos, la Organización de las Naciones Unidas, Amnistía Internacional, Programas de las Naciones Unidas para el desarrollo, Human Rights Watch, Unicef, Unesco, Tribunales Europeos de Derechos Humanos, entre otros; direccionan las políticas educativas en el conocimiento y respeto de los Derechos Humanos.

Políticas que asume el gobierno nacional a través del Ministerio de Educación creando sus directrices y dando pautas de elaboración de los Manuales de Convivencia a las instituciones educativas tanto públicas como privadas, herramienta pedagógica que regula el funcionamiento interno y guía los procesos formativos de los estudiantes mediante normas que promueven el respeto de los Derechos Humanos y la igualdad de las niñas, los niños y los jóvenes. Sin embargo, algunos de estos instrumentos no incorporan los 
estándares establecidos por los órganos nacionales e internacionales y, por el contrario, son incompatibles, incluso con la legislación nacional, rechazando la validez del derecho a la educación y la educación en Derechos Humanos.

De igual forma, a nivel profesional es poco el desarrollo de la cátedra y/o asignatura en Derechos Humanos en las instituciones de pregrado que impartan carreras de licenciatura en el país; por lo que se hace imprescindible generar una política estructural que haga posible la inserción de una cátedra obligatoria en Derechos Humanos y/o educación en Derechos Humanos; para que de esta forma se garantice el respeto, la promoción y divulgación de los Derechos Humanos en todos los campos institucionales y sociales, especialmente en la escuela.

El desarrollo de este artículo busca crear conciencia de la importancia de la educación en Derechos Humanos y, especialmente, en el conocimiento que deben tener los docentes y directivos docentes en esta cátedra, sin importar la asignatura que impartan o nivel directivo en el que se encuentren.

\section{ANTECEDENTES:}

Los avances en tema de educación en Colombia y en la aplicación del Derecho a la Educación desde mediados del siglo XX hasta la actualidad, han mostrado resultados notorios en el factor social del país. Esto se evidencia en la inversión en infraestructuras educativas, inclusión de escuelas rurales, programas para la prevención de la deserción escolar, convenios con el Servicio Nacional de Aprendizaje (SENA), en la articulación de la educación básica y media con la educación para el trabajo, entre otros. 
Para el siglo pasado, las dificultades en materia de educación tales como: las bajas tasas de escolaridad, la falta de maestros y algunos con poca preparación, Helg (1987, pág. 281): "eran pocos los que habian estudiado en la Escuela Normal Superior; la cantidad de licenciados que egresaban cada año de ella eran ocupados en los colegios nacionales y en los establecimientos privados de prestigio, antes de pasar a la universitaria. La mayoría de los profesores eran antiguos maestros de primaria o bachilleres que repetían la enseñanza recibida en el colegio"; y las altas tasas de analfabetismo, especialmente en jóvenes y adultos, ya que "el 41\% de la población de 15 o mas años de edad era analfabeta, el 50\% declaró tener instrucción primaria, el 7\% secundaria, el 0.9 universitaria el resto, otro tipo de instrucción” (Planeación, 1961), con poca inversión y poca atención de los gobiernos y, en presupuesto y desarrollo institucional los planes de desarrollo no contemplaban mayores inversiones, tal es evidente en los documentos del DNP que en 1987 señalan: "A las diferencias de cobertura se suman limitaciones en la calidad de los servicios. El crecimiento de la oferta educativa no ha sido apoyada por un avance equivalente en la eficiencia interna del sector” (Departamento Nacional de Planeación, 1987)

Además, la educación se centraba en la estabilidad de la educación privada, en su mayoría, direccionada por la iglesia, "el papel del maestro, como prolongación de la misión de los apóstoles de Cristo en la tierra era formar a los niños bajo los principios del pensamiento judeocristiano soportados en la religión católica y consignados en el catecismo moral” (Universidad Distrital Francisco José de Caldas, 2003, pág. 103). Desde el gobierno del Presidente Rojas Pinilla, se hicieron muchas concesiones a la iglesia, tales como: la pronunciación "en favor de una organización social acorde a los principios católicos [...] concedió a los hermanos cristianos el derecho a tener su propio plan de 
estudio,[...] El estado sostuvo el programa de alfabetización de acción cultural popular de la iglesia” (Helg, 1987, pág. 222).

A mediados de los años ochenta, se buscó implementar un sistema educativo diseñado para disminuir la brecha social, se crea el plan quinquenal de educación caracterizado por dejar a un lado la influencia total de la iglesia (Deas, 1990), aunque esta influencia abrevia únicamente con la puesta en marcha de la Constitución Política de Colombia de 1991, ya que ésta se centra en el Estado laico y, para ello la "escuela debe ser única y estar en manos del Estado” (Zuretti, 1988, pág. 271).

Con el aumento de instituciones educativas de carácter público y privado, se aumenta el número de niños y jóvenes que ingresa al sistema educativo, específicamente en el sector público; la educación se ve como el aporte de mano de obra calificada y, por ello, se direcciona la educación en el saber y saber hacer ${ }^{1}$, orientando a una educación práctica y técnica, teniendo en cuenta la ley 115 de 1994 y los fines de la educación, como se observa en "La formación en la práctica del trabajo, mediante los conocimientos técnicos y habilidades, así como en la valoración del mismo como fundamento del desarrollo individual y social (Ministerio de Educación Nacional, 1994).

Actualmente, los problemas de cobertura y calidad están en vía de superación, pero el de capacitación y formación docente, especialmente en derechos humanos, es un tema que aun deben resolver los gobiernos y planes venideros fundamentados en las directrices internacionales.

\footnotetext{
${ }^{1}$ Los Estándares de competencias ciudadanas propuestos por el MEN, establecen que los estudiantes deben Saber y Saber hacer, tener conocimiento, utilizarlo en el espacio, lugar y momento adecuado.
} 
Para 1991 y la entrada en vigor de la Constitución Política de Colombia de 1991, el Estado colombiano ya había suscrito varios pactos y acuerdos internacionales que lo comprometían en la garantía de los derechos humanos: "la carta de 1991 confirma y refuerza tanto la obligatoriedad del derecho internacional de los derechos humanos como la del derecho internacional humanitario" (Oficina en Colombia del Alto Comisionado de las Naciones Unidas para los Derechos Humanos, 2003, pág. 157); estos pactos, tratados y acuerdos internacionales tienen una índole de obligación jurídica explícita contraída por los Estados partes, como se explica a continuación.

\section{LA EDUCACIÓN Y LOS TRATADOS E INSTRUMENTOS INTERNACIONALES:}

La educación es el eje principal para la promoción, divulgación y defensa de los Derechos Humanos, ya que, en sí misma es un articulado propio reconocido y consagrado en la Declaración Universal de los Derechos Humanos ${ }^{2}$; el Pacto Internacional de los Derechos Económicos, Sociales y Culturales de las Naciones Unidas ${ }^{3}$; Declaración Americana de los Derechos y Deberes del Hombre, ${ }^{4}$ la Convención sobre la Eliminación de

\footnotetext{
${ }^{2}$ Aprobada por las Naciones Unidas adoptada por la Asamblea General en su resolución 217 A, de 10 de diciembre de 1948, art.26, toda persona tiene derecho a la educación (...) tiene por objeto el pleno desarrollo de la personalidad humana y el fortalecimiento del respeto a los derechos humanos.

${ }^{3}$ Adoptado en 1966, entrada en vigor para Colombia el 3 de enero de 1976 en virtud de Ley 74 de 1968 , art.13, el presente pacto reconoce el derecho de toda persona a la educación(...)la educación debe orientarse hacia el pleno desarrollo de la personalidad humana y del sentido de su dignidad, y debe fortalecer el respeto por los derechos humanos; y art. 14, todo Estado parte... se compromete a elaborar y adoptar (...)un plan detallado de acción para la aplicación progresiva, dentro de un numero de años fijado en el plan, el principio de la enseñanza obligatoria y gratuita para todos.

${ }^{4}$ Aprobada en la Novena Conferencia Internacional Americana, Bogotá, en abril de 1948; art. XII, Toda persona tiene derecho a la educación la que debe estar inspirada en los principios de libertad, moralidad y solidaridad humana (...) mediante esa educación, se le capacite para lograr una digna subsistencia, en mejoramiento del nivel de vida y para ser útil a la sociedad.
} 
Todas las Formas de Discriminación Contra la Mujer ${ }^{5}$, el Protocolo Adicional a la Convención Americana sobre Derechos Humanos en materia de Derechos Económicos, Sociales y Culturales ${ }^{6}$; también es reconocido en la Convención sobre los Derechos del Niño ${ }^{7}$. (Oficina en Colombia del Alto Comisionado de las Naciones para los Derehos Humanos, 2003).

Por el compromiso ético y político y, en busca del respeto de la dignidad humana en el mundo, los Estados han incorporado estos y demás instrumentos, pactos y protocolos para que formen parte del ordenamiento jurídico de los Estados.

De estos instrumentos el que consagra de mejor manera el derecho a la educación es El Pacto Internacional de los Derechos Económicos, Sociales y Culturales de las Naciones Unidas. De acuerdo con lo que se estipula en la segunda parte de este documento, los Estados Partes en el presente pacto se comprometen a garantizar el ejercicio de los derechos que en él se enuncian, sin discriminación alguna, buscando su progresividad, específicamente el art. 13, enuncia una serie de recomendaciones refiriéndose con ello a que abarca no solo la cobertura sino todos los aspectos que busquen mejorar la calidad humana y la vida digna, teniendo en cuenta la accesibilidad, adaptabilidad y permanencia.

\footnotetext{
${ }^{5}$ Adoptada por la Asamblea General en su resolución 34/180, de diciembre de 1979, entrada en vigor para Colombia el 19 de febrero de 1982, establece, en el artículo 10, la obligación del Estado de adoptar medidas para eliminar la discriminación contra la mujer en la esfera de la enseñanza.

${ }^{6}$ Protocolo de San Salvador, suscrito en el Salvador el 17 de noviembre de 1988, entrada en vigor para Colombia el 16 de noviembre de 1999 en virtud de la ley 319 de 1996, art. 13, toda persona tiene derecho a la educación.

${ }^{7}$ Proclamada por La Asamblea General de las Naciones Unidas en su resolución 44/25, del 20 de noviembre de 1989 entrada en vigor para Colombia en enero de 1991, en virtud de la ley 12 de 1991, arts. 19, los Estados partes adoptaran todas la medidas legislativas, administrativas, sociales y educativas aprobadas para proteger al niño contra toda forma de prejuicio o abuso físico o mental (...) y art. 28, los Estados partes reconocen el derecho del niño a la educación (...) adoptaran cuantas medidas sean adecuadas para velar porque la disciplina escolar se administre de modo compatible con la dignidad humana del niño y de conformidad con la presente convención.
} 
El instrumento que dedica su esencia a los derechos de las niñas y los niños, es la Convención de los Derechos del Niño, en su preámbulo reza que: "Recordando que en la Declaración Universal de Derechos Humanos las Naciones Unidas proclamaron que la infancia tiene derecho a cuidados y asistencia especiales" y, que "el niño debe ser educado en el espíritu de los ideales proclamados en la Carta de las Naciones Unidas y, en particular, en un espíritu de paz, dignidad, tolerancia, libertad, igualdad y solidaridad". Kofi Annan dijo que "sin Derechos Humanos no puede haber paz ni prosperidad duraderas" (Naciones Unidas , 2004, pág. 13); por ello la cantidad de mecanismos y procedimientos, grupos de trabajo, informes, planes y programas para implementación y defensa de los Derechos Humanos a nivel nacional.

Los organismos de las Naciones Unidas que se encargan de la protección, promoción y defensa de los Derechos Humanos son la Organización de las Naciones Unidas para la Educación, la Ciencia y la Cultura, Unesco ${ }^{8}$; el Comité de los Derechos Sociales, Económicos y Culturales, que funciona desde 1987 y que tiene como finalidad la calidad de vida y el bienestar social de las personas, especialmente el goce del derecho a la educación y el derecho a la educación en Derechos Humanos; el cual no debe estar sujeto a la coyuntura económica y política, sino que debe ir incorporándose a programas y planes Estatales progresivos y de obligatorio cumplimiento, cuya protección se halle claramente establecida en el ordenamiento y la jurisprudencia interna.

El sistema interamericano de los derechos humanos conforma otro referido de importancia para la promoción y protección del derecho a la educación, constituido por dos

\footnotetext{
${ }^{8}$ Es un organismo especializado de las Naciones Unidas. con el objetivo de contribuir a la paz y a la seguridad en el mundo mediante la educación, la ciencia, la cultura y las comunicaciones
} 
instancias independientes y complementarias donde se pueden denunciar las violaciones de los derechos por parte de los Estados, estas son: La comisión Interamericana de Derechos Humanos (CADH), “es un órgano principal y autónomo de la Organización de los Estados Americanos [...] fue creada para promover la observancia y defensa de los Derechos humanos y servir como órgano consultivo" y la Corte Interamericana de Derechos Humanos, (CIDH) es "una institución jurídica autónoma, cuyo objetivo es la aplicación e interpretación de la Convención Americana sobre Derechos Humanos" (Huertas D., Cáceres T., Nathalia, \& Gómez C., 2005, págs. 299 - 301).

El sistema Interamericano cuenta con un órgano auxiliar de naturaleza académica; el Instituto Interamericano de Derechos Humanos, dedicado a la investigación, la promoción y la educación en derechos humanos; promueve el respeto de los derechos humanos establecidos en los pactos y tratados del sistema interamericano por medio de la educación y la formación en derechos humanos.

Todas las normas y disposiciones institucionales "constituyen hoy un código universal de conducta y un criterio compartido de legitimación de las instituciones políticas” (Defensoría del Pueblo, 2001, pág. 10), que le permiten a la persona reclamar lo que necesita para vivir de manera digna y para cumplir con los fines propios de la vida en comunidad, las mismas disposiciones institucionales fomentan mediante la educación el conocimiento de los Derechos Humanos que "se han incorporado a la educación formal junto con otros temas como el medio ambiente, multiculturalidad, orientación sexual, salud, educación para el consumo, etc., en perspectiva de la formación ciudadana, la formación para la vida y la formación para la vida democrática” "” (Magendzo, 2005, pág. 19). 


\section{DERECHOS DE LOS NIÑNOS Y LAS NIÑAS:}

Las niñas y los niños son las principales víctimas de las desigualdades sociales de los pueblos, por su propia condición de vulnerabilidad son dependientes de los mayores y, de las decisiones que se tomen en nombre de ellos.

La convención sobre los Derechos de la Niñez define como niño o niña " $a$ toda persona menor de 18 años, a menos que las leyes de un determinado país reconozcan antes la mayoría de edad. En algunos casos, los Estados tienen que ser coherentes a la hora de definir las edades para trabajar y para hacer parte del sistema educativo” (Oficina en Colombia del Alto Comisionado de las Naciones Unidas para los Derechos Humanos, 2003, pág. 487). Los Estados Partes están en la obligación de garantizar a todos los niños el beneficio de una serie de medidas enunciadas en 41 artículos para la protección y el desarrollo armonioso de los niños.

En el encuentro Sudamericano de Seguimiento al Estudio de las Naciones Unidas sobre la Violencia contra niños, niñas y adolecentes, llevado a cabo en Asunción los días 28 y 29 Abril 2011, para prevenir la violencia que trae consecuencias devastadoras para la salud y el bienestar de la infancia y juventud ahora y en el futuro; tiene como base la Convención de los Derechos del Niño, ratificada por todos los Estados participantes.

De este encuentro se obtienen seis recomendaciones que buscan unificar estrategias para prevenir y sancionar la violencia contra las niñas y los niños como son: “la creación de un organismo regional de denuncias, la prohibición de prácticas tradicionales dañinas en todos los ámbitos, como puede ser la educación tradicional (la letra con sangre, entra), 
prohibición de la violencia contra los NNA incluso con objetivos "correctivos”; en algunos casos los instrumentos comportamentales, capacitación a funcionarios, docentes y directivos que tienen a su cargo el cumplimiento o la vigilancia de alguno de los derechos de NNA, se investiguen otros tipos de violencia como la estructural y la simbólica, con la finalidad de generar políticas públicas que reviertan esta situación”, (Otero, 2011, pág. 49), fortaleciendo las instituciones para que los mecanismos de denuncia sean accesibles, adecuados y tenidas en cuenta para prevenir la violencia contra la niñez.

Este es un documento valioso para tener en cuenta en los diferentes ámbitos de legislación o normas que vinculen el desarrollo psicosocial de las niñas y los niños como lo es la educación, los estándares y las competencias educativas, en busca de la construcción de un proyecto educativo incluyente que vaya en contravía de la violencia contra los niños y las niñas.

\section{LA EDUCACIÓN COMO DERECHO CONSTITUCIONAL}

Por mandato constitucional la Carta Magna reza en el Preámbulo: [...] “con el fin de fortalecer la unidad de la Nación y asegurar a sus integrantes la vida, la convivencia, [...] el conocimiento, la libertad y la paz, dentro de un marco jurídico, democrático y participativo que garantice un orden político, económico y social justo, [...] decreta” en su TITULO I, art. 1. Que "Colombia es un Estado social de derecho, [...] fundada en el respeto de la dignidad humana, y en la prevalencia del interés general’. Art. 2. Son fines esenciales servir a la comunidad, promover y garantizar la efectividad de los principios, derechos y deberes consagrados en la Constitución; y art.5. Reconoce, sin discriminación alguna, la primacía de los derechos inalienables (Presidencia de La Republica, 2011). 
Teniendo en cuenta estos preceptos constitucionales y que el Estado colombiano hace parte de las declaraciones y tratados internacionales, el Estado no solo debe gobernar y administrar justicia, sino que tiene la obligación de garantizar el bienestar del pueblo y su participación.

El Estado Social de Derecho le da características a la nación de tener un objetivo social, por lo tanto, el Estado pasa a convertirse en el principal participante de la dinámica del desarrollo social dejando de ser un simple administrador y está constituido como un Estado Constitucional de Derecho. En él la Constitución es la norma fundamental del orden jurídico del Estado, en el sentido de la teoría pura del Derecho, así como también es un todo normativo, más allá de su consideración meramente programática.

En la constitución Política de Colombia, de acuerdo a su contenido, se tienen diferenciados los derechos: los primeros civiles y políticos (también llamados libertades fundamentales), que defienden a los ciudadanos frente al poder del Estado y; los derechos económicos, sociales y culturales, los cuales tienen una exigencia de intervención del Estado para garantizar el acceso igualitario a los derechos y compensar las desigualdades por clases, religión, sexo, etnia, etc., en busca de una existencia digna.

Sin importar las razones de división, sean históricas o políticas, en la práctica, ambos son completamente interdependientes, indivisibles e inviolables.

La educación como derecho aparece consagrado en la constitución política en el Titulo 1l, Capitulo 2. El cual trata de los derechos sociales, económicos y culturales; en el artículo 44, habla de los derechos fundamentales de los niños, donde integra el derecho a la educación, y el artículo 67, que define la educación como un derecho de la persona y un servicio público. 
Para dejar de lado las ambigüedades que deja la carta magna con relación al derecho a la educación, fue la corte desde su jurisprudencia quien ha ido aclarando temas puntuales, tales como la doble connotación como derecho fundamental y como servicio público, es así como en la Sentencia T-779/11, (Derecho a la educación,Tratamiento constitucional con doble connotación como derecho y como servicio, 2011) la corte aclara que: "Cuando la Sala habla de accesibilidad o acceso a la educación, hace referencia a que el Estado debe implementar políticas públicas, programas y actividades que estén dirigidos a alcanzar las condiciones de infraestructura mínimas necesarias para permitir el acceso, la continuación y la eficacia en la prestación del servicio”; de esta forma se garantiza la protección del derecho a la educación.

También lo precisa la Constitución Política de Colombia en su Artículo 93, que inscribe que los derechos internos están supeditados por los tratados y convenios internacionales ratificados por Colombia (Presidencia de La Republica, 2011); el Art. 67 de la Constitución Política emana: "la educación formará al colombiano en el respeto de los derechos humanos, a la paz y a la democracia; y en la practica del trabajo y la recreación, para el mejoramiento cultural, científico, tecnológico y para la protección del medio ambiente (...)por la mejor formación moral, intelectual y física de los educandos" (Presidencia de La Republica, 2011).

La educación no tiene fines únicamente teóricos, tiene que ver con los retos sociales y culturales, la transmisión de saberes sobre determinados temas o propuestas, en torno a esto la corte dice: "se reconoce al "conocimiento" como uno de los fines del Estado. Asimismo si pasamos revista del cuerpo normativo, encontramos entre otras las siguientes disposiciones que se refieren al tema: el deber estatal de "promover y fomentar el acceso a la cultura de todos los colombianos en igualdad de oportunidades, por medio de la 
educación permanente” ” (Tutela, Derecho a la educación, 1998), la educación se articula con la educación para forjar la identidad cultural, el ser social y el libre desarrollo a la personalidad con la finalidad de estructurar un ser cuya prioridad sea la vida digna.

"Todo lo que es especificamente humano tiene su origen en la comunidad" (Zuretti, 1988, pág. 271), la educación es el campo por excelencia para la socialización, la vivencia con el otro y especialmente como dispositivo de poder, por ello la importancia de tener conocimientos específicos en una pedagogía de los Derechos Humanos, que interiorice los tratados, acuerdos y recomendaciones nacionales e internacionales.

La escuela cumple con una acción social de vivencia en comunidad, por ello su deber de educar al ser individual, con valores y prejuicios para llegar a un consenso donde la exclusión sea mínima. La educación en derechos humanos otorga herramientas a los diferentes grupos sociales para generar una nueva cultura de organización, de representación mental de las prácticas políticas y de los sujetos que las realizan para convocar a una participación con poder de decisión que genere un compromiso social, "Poner la educación al servicio de la paz es el ideal por el que han trabajado y trabajan muchos hombres en el mundo, la necesidad de una pedagogía de la paz surge de un análisis profundo de la realidad” (Rayo, 1993, pág. 35).

PLANES NACIONALES DE EDUCACIÓN Y EDUCACIÓN EN DERECHOS HUMANOS:

La educación es un proceso de formación permanente, personal, cultural y social que se fundamenta en una concepción integral de la persona humana, de su dignidad, de sus derechos y de sus deberes. La educación propende por alcanzar una relación armónica entre 
la escuela y su entorno, hacia un horizonte de convivencia que propenda por la dignidad humana.

El gobierno, a través del Ministerio de Educación ha abordado compromisos para direccionar a los colegios en la educación de los Derechos Humanos, desde las obligaciones constitucionales, teniendo en cuenta los acuerdos, leyes y planes estatales y locales establecidos por los acuerdos y tratados internacionales con el fin de promover y proteger la dignidad humana, para que los Derechos Humanos se hagan efectivos para las niñas y los niños y se evite su vulneración.

No obstante, se han venido desconociendo realidades sociales, y este deber Estatal de proteger los derechos de las niñas y los niños ha sido enmarcado en políticas que buscan homogeneizar e imponer modelos de comportamiento bajo relaciones de poder sin respetar la diversidad, la pluralidad y limitando las posibilidades de conocimiento y reconocimiento de los derechos a la infancia y sus familias.

La implementación de planes y políticas del MEN que se llevan a cabo en las instituciones educativas públicas y privadas, en algunos casos se han quedado en la opción de una serie de actividades puntuales, como talleres, grupos de estudio, proyectos internos, etc., que si bien al elaborar los proyectos se tienen en cuenta los preceptos constitucionales colombianos, los contenidos jurídicos y las recomendaciones nacionales e internacionales; en su mayoría desconocen sus fundamentos y no adoptan medidas administrativas, legislativas, judiciales, económicas, sociales ni de política pública para asegurar el pleno goce del derecho a la educación, cuyo objetivo sería asistir a los grupos poblacionales más vulnerables. 
Desde la promulgación de la Ley General de Educación?', las instituciones educativas deben impulsar un proyecto educativo institucional que debe ir de acuerdo a la realidad de los estudiantes y al contexto social que los rodea y permea; y deben construir un conocimiento desde la escuela para toda la comunidad educativa, especialmente la familia. El servicio de educación debe cumplir "una función social acorde con las necesidades e intereses de las personas, de la familia y de la sociedad. Se fundamenta en los principios de la Constitución Política sobre el derecho a la educación que tiene toda persona, en las libertades de enseñanza, aprendizaje, investigación y cátedra y en su carácter de servicio público” (Ministerio de Educación Nacional, 2003), de ahí que, debe adoptar medidas hasta el máximo de los recursos disponibles para maximizar la aplicación del derecho a la educación para lograr la efectividad del disfrute del mismo buscando la progresividad y eficacia.

De igual forma, a nivel Nacional, el MEN está llevando a cabo un proyecto de Educación en Derechos Humanos "EDUDERECHOS"10 que se apoya en proyectos, planes y trabajos de Derechos Humanos llevados a cabo en las diferentes instituciones educativas.

Éste brinda una serie de módulos, que buscan concretar trabajos al interior de las instituciones educativas con relación a la enseñanza de los Derechos Humanos, "Los módulos que componen esta primera serie constituyen una ruta para la implementación de los proyectos pedagógicos de educación para los derechos humanos en las instituciones

\footnotetext{
${ }^{9}$ La educación está reglamentada por la ley 115 de 1994 o ley general de educación. La política pública en educación se define a través del plan decenal de educación y los planes sectoriales de educación en los niveles nacional, departamental, distrital y municipal.

${ }^{10}$ Eduderechos, hace presencia en 23 secretarías del país, para el 2014 pretende llegar a la totalidad de secretarias de educación en Colombia desde el segundo semestre de 2011 el Programa adelanta acciones conjuntas con la Oficina del Alto Comisionado de las Naciones Unidas para los Derechos Humanos (Oacnudh) en algunas secretarías de educación con el propósito de contribuir desde el sector educativo, a posicionar la temática de educación en Derechos Humanos en las políticas públicas locales.
} 
educativas y un elemento de trabajo para otros actores estratégicos" (Ministerio de educación, 2010).

Así, este programa recoge las experiencias en educación de los Derechos Humanos que se llevan a cabo con los estudiantes de las instituciones educativas y, en algunos casos, con la comunidad escolar; para que en la educación, el ejercicio de los derechos humanos sea una realidad en la cotidianeidad escolar.

El Planedh (Plan Nacional de Educación en Derechos Humanos), es el Plan Económico y Social Nacional, articulado a Eduderechos, y su propósito es el de poner en marcha proyectos a nivel nacional tanto en lo público como en lo privado, e inyectar presupuestos y más presión política a los programas de educación en Derechos Humanos, su finalidad "es constituirse en una política pública de educación en Derechos Humanos, centrada en la formación de sujetos activos de derechos, la consolidación del Estado Social de Derecho y la construcción de una cultura de Derechos Humanos en el país” (Ministerio de Educación, 2012). Para hacer efectivo este presupuesto trabajan en equipo "el Ministerio de Educación Nacional, la Defensoría del Pueblo y el Programa Presidencial de Derechos Humanos de la Vicepresidencia de la República, con el acompañamiento de la Oficina del Alto Comisionado de las Naciones Unidas para los Derechos Humanos (OACNUDH) y el Programa de Derechos Humanos USAID-MSD” (Ministerio de Educación, 2012).

Con el presupuesto adicional exclusivo para la Educación en Derechos Humanos gracias al crédito del Banco Interamericano de Desarrollo(BID), por valor de 12 millones de dólares, "para el desarrollo de programas pedagógicos transversales que desarrollen las competencias ciudadanas" (Ministerio de Educación, 2012), se espera mayor inversión 
en programas, planes y proyectos al interior de las instituciones educativas, incluyendo a las instituciones superiores a nivel nacional, como seria la implementación de la obligatoriedad de la catedra de los Derechos Humanos a nivel profesional.

En el Plan Decenal de Educación, 2006-2015, Pacto Social por la Educación que determina el horizonte de la educación en el país para 10 años, allí se compromete a todos los entes educativos del Estado para hacer posible el derecho a la educación, "Su fundamento es la garantía del derecho a una educación de calidad para toda la población colombiana en edad escolar, cuya principal responsabilidad recae en el Estado” (Ministerio de Educación Nacional, 2008). Su objetivo primordial es convertirse en un pacto social, en donde intervienen las instituciones públicas, privadas y la comunidad en general en busca de transformaciones estructurales en la educación. Para posibilitar y darle cuerpo a este plan decenal, es importante incluir sus planteamientos, en todos los Planes de Desarrollo Territorial y en los planes sectoriales.

Colombia, en su intervención en el informe Anual de Actividades ante la Comisión General del Consejo Permanente de la Organización de los Estados Americanos (OEA), llevado a cabo el pasado 20 de marzo de 2012, dio a conocer:

1. "La construcción del Plan de Acción 2011-2015, subrayando especialmente la importancia de que fue el resultado de un proceso "altamente participativo de concertación y consensuado, conforme a las necesidades de los países en sus diferentes enfoques regionales"; 2. el Proyecto de Promoción y Protección de los Derechos de los Niños, Niñas y Adolescentes en el Sistema Interamericano, financiado por la Agencia Canadiense de Cooperación Internacional (ACDI) y del que Colombia forma parte como país beneficiario; 3. Fortalecer sus políticas 
públicas, legislación y sistema de seguimiento y monitoreo de derechos” (Instituto Interamericano del Niño, la Niña y Adolescentes., 2012).

Este informe confirma que Colombia cuenta con apoyo a nivel internacional para fortalecer los planes y proyectos direccionados a proteger a los niños, niñas y jóvenes contra todo tipo de violencia, disminuyendo la exclusión social, con una educación de calidad para el desarrollo e integración de las sociedades.

Es importante destacar que "la adopción de algunas normas, la ratificación de tratados internacionales y progresos en la elaboración del Plan de Educación en Derechos Humanos" (Naciones Unidas, Consejo Económico y Social., 2006), en Colombia, en educación para los Derechos Humanos y la obligatoriedad de la progresividad, queda faltando en los planes nacionales intervención en la Educación profesional, para que desde allí se empiece a formar a nuestros docentes en Derechos Humanos y de esta forma sea posible la vivencia de los Derechos Humanos en la educación.

"No se puede reflexionar sobre la educación, sin una reflexión del propio ser humano en cuya naturaleza existencial encontramos el núcleo de sustentación de la acción educativa" (Olivera, 2002, pág. 48); el respeto al estudiante, trabajar en los proyectos de aula, teniendo en cuenta las características de la población y su propio conocimiento, dejar de lado el autoritarismo, son algunos de los elementos importantes para el desarrollo democrático de las clases y la comprensión de la realidad.

Pensando especialmente en la educación y educación en Derechos Humanos de los niños, niñas y jóvenes, aquellos que serán las generaciones adultas, es necesario analizar y reflexionar sobre la políticas educativas, especialmente las que llegan directo al aula, y la importancia de la formación docente, pues se convierte en un tema primordial para alcanzar 
todas esas metas vistas por las organizaciones nacionales e internacionales, "La Conferencia Mundial de los Derechos Humanos pide a todos los Estados e instituciones que incluyan los derechos humanos, el derecho humanitario, la democracia y el imperio de la ley como temas de los programas de estudio de todas las instituciones de enseñanza académica y no académica” (Defensoria del Pueblo, 2009, pág. 24).

El sistema educativo debe tener inmersa la intencionalidad de educar para el futuro de la nación, desatar en los niños, niñas y jóvenes la autorregulación de su actuar, su sentir y pensar y, para ello se debe actuar en la mente de los niños con los elementos tomados de la realidad y no con reglas abstractas, y se debe enseñar más con la ayuda de objetos que de palabras (Manacorda, 1987, pág. 413); para que la reflexión y acción existan en su propia experiencia. "En muchos casos, el saber escolar no llega a ser objeto de una apropiación real; es apenas materia de un aprendizaje que no lo integra en la red de explicaciones que el individuo a hecho propias y que emplea de manera relativamente espontanea para responder preguntas o resolver problemas” (Mockus, 1997, pág. 31).

\section{BOGOTÁ, EDUCACIÓN EN DERECHOS HUMANOS:}

"La construcción de esa ciudad se fundamenta en una política, en una decisión que ponga en su centro el respeto, la protección y la promoción de los derechos de todos y cada una de las personas que en ella habitan” (Alcaldia Mayor de Bogotá, Secretaria de Gobierno, 2007, pág. 11)

En Bogotá se viene implementando una Cátedra de Derechos Humanos que busca la construcción de una comunidad educativa que reconozca los derechos humanos y así 
mismo los pueda divulgar, respetar, exigir y entender cómo la violación de tales derechos afecta directamente a las niñas y los niños.

"La cátedra es un espacio para la construcción de una cultura a favor del respeto, la vivencia, la enseñanza y la formación de Derechos Humanos”. (Alcaldia Mayor de Bogotá, Secretaria de Educación, 2005, pág. 24); Ya que Bogotá es una ciudad múltiple, fragmentada, un escenario donde convergen personas de todo el país, donde se concentra casi toda la información y, en especial, es el refugio obligado de la violencia rural; las instituciones educativas tienen una gran labor teniendo en cuenta esta población que caracteriza cada una de ellas.

Por eso la hegemonía debe romperse, los proyectos deben ser construidos y desarrollados en cada y para cada institución, especialmente los proyectos de Derechos Humanos. La escuela cumple con una acción social de vivencia en comunidad, por ello su deber de educar al ser individual, con valores y juicios que generen un compromiso social.

En cada institución del Distrito, acorde con las políticas estatales, se siguen los lineamientos del MEN, incorporando el manual de convivencia como proyecto para mejorar la convivencia: es una herramienta legal con la cual cuentan las instituciones escolares para promover el respeto por los derechos humanos, la igualdad de las niñas y los niños y favorece la convivencia pacífica; los objetivos de estos manuales es que "los estudiantes se formen de manera integral y a su vez tengan claridad de la existencia de límites en el ejercicio de su libertad y autonomía" decreto 1860 art.17, (Ministerio de Educación Nacional, 1994). 
El MEN da recomendaciones para la elaboración de estos manuales con referentes tales como: Cultura de los Derechos Humanos, Dignidad Humana, Corresponsabilidad, Ciudad de Derechos, Reconocimiento a la diversidad, inclusión, interculturalidad y perspectiva de género; sin embargo, las instituciones educativas tienen autonomía a la hora de elaborar este instrumento, de ahí que si hay falencia en conocimientos específicos en temas como derechos humanos y pedagogía, se corre el riesgo que sea un dispositivo en busca de obediencia perdiendo su función pedagógica que direccione la dignidad humana.

Los manuales de convivencia de los colegios y demás instituciones educativas constituyen complejos normativos internos, [...] en los cuales se dejan previamente establecidas las reglas de juego que presidirán las relaciones entre unos y otros y que habrán de regir la vida académica y demás actividades propias de la prestación del servicio público educativo, todo dentro de las previsiones y limitantes de la Constitución y la ley. [...] es necesario el previo y pleno conocimiento de su contenido (Tutela 618 de 1998, Reglamento Educativo, 1998). Por esta razón es trascendental llevar a cabo un seguimiento de cómo es la elaboración y la utilidad que le dan las Instituciones educativas a este instrumento, y poder hacer algunas recomendaciones en aras de la Vivencia de los Derechos Humanos en la escuela.

Toda herramienta que sirva para proteger los Derechos Humanos debe ser establecida en el conocimiento de los tratados y acuerdos internacionales y acorde a la Constitución Política de Colombia; por esto los manuales de convivencia escolar, deben ser elaborados acorde a la población de cada institución educativa, identificando mecanismos y procedimientos para la prevención y resolución de conflictos de una manera creativa y pacífica, evitando imponer normas que vayan en contravía de las diferencias individuales. 
La transformación de la escuela asocia cambios en la profesionalización docente y, por ende, en las prácticas pedagógicas, en los proyectos de aula y en los proyectos institucionales que se ven reflejados al interior de las aulas; acciones en las que interviene directamente el docente, como en la elaboración de instrumentos de normas comportamentales, como los manuales de convivencia y los Proyectos de Derechos Humanos.

El docente debe romper con el esquema de poder unidireccional ya que la "acción se ve como una conducta portadora de sentido, algo especial que, preñándola, le da su fundamento, para que desde este modo constituirse, en la base de las relaciones sociales” (Ricardo Garcia Duarte, 2004, pág. 7); siendo el niño, la niña o el joven quien en última instancia sea la base de esa relación y se refleje en su accionar social.

En las instituciones educativas los manuales de convivencia son, además, instrumentos comportamentales que no tienen en cuenta los derechos de los niños, niñas y jóvenes, ni sus opiniones; muestra de esto son las tutelas interpuestas por fallas en el reglamento educativo como la Tutela 618 de $1998^{11}$, la sentencia de Tutela 695 de 1999 , (Tutela 695 de 1999, Reiteración de Jurisprudencia, 1999) ${ }^{12}$ y Tutela 345 de 2008 (Tutela 345 de 2008, 2008) ${ }^{13}$, las decisiones institucionales son excluyentes por la apariencia

\footnotetext{
${ }^{11}$ Para que los manuales de convivencia sean documentos oponibles y exigibles a padres de familia y estudiantes, se hace menester su expresa aceptación, libre y espontánea, expresada en el momento de la matrícula, y, claro está, para que ella a la vez se produzca, es necesario el previo y pleno conocimiento de su contenido.

12 Tema: Reiteración de la jurisprudencia consagrada en las sentencias SU 641 y SU 642 de 1998 relativa a la prohibición de establecer criterios estéticos excluyentes como faltas disciplinarias en la prestación del servicio público de educación, salvo que se trate de preservar la vida y la integridad física de los alumnos.

${ }^{13}$ El Derecho fundamental al libre desarrollo de la personalidad frente a las normas de los manuales de convivencia de las instituciones educativas que prohíben llevar el cabello largo. Reiteración de jurisprudencia
} 
personal, (que si bien es importante en los valores estéticos) dejan de lado el verdadero significado del respeto a la diferencia y a la libre determinación .

Los manuales de convivencia y los proyectos de Derechos Humanos son direccionados por los docentes, que a su vez son capacitados en competencias comunicativas, discursivas y pedagógicas entre otras, hallando que en los últimos concursos la incorporación de docentes no tiene en cuenta la exigencia de estar inscritos en el "escalafón docente" y la convocatoria es abierta a cualquier profesional, quienes en su mayoría, aunque son excelentes profesionales, no son pedagogos ni tienen conocimientos específicos en Derechos Humanos.

Teniendo en cuenta una encuesta ${ }^{14}$, realizada a docentes de diferentes áreas e instituciones del distrito capital, se evidencia la falta de conocimientos en Derechos Humanos, ya que en la mayoría de instituciones universitarias no se dicta esta cátedra, por ello, a la hora de implementar la cátedra al interior de las instituciones educativas de básica y media, se queda en tareas y evaluaciones puntuales y/o en la elaboración de instrumentos que justifiquen la homogenización, "Es débil la inclusión de cátedras y asignaturas en la educación en Derechos Humanos, en la educación de profesionales de las ciencias sociales y la salud, la formación en derechos humanos es casi excepcional” (Defensoria del Pueblo, 2009, pág. 60).

La educación y la educación en Derechos Humanos tienen una responsabilidad fundamental en el Estado, y en los docentes por que "La instrucción sirve a la educción,

\footnotetext{
${ }^{14}$ La encuesta fue realizada en septiembre del año 2011, con 5 preguntas como: Institución donde terminó el pregrado, título obtenido, área que imparte, ¿dentro del pregrado está la materia de derechos humanos, ha visto la cátedra en derechos humanos? realizada a 230 docentes en colegios del distrito de la localidad Rafael Uribe Uribe y en 3 colegios privados.
} 
pero no toda instrucción influye educativamente. Con el mero saber y conocer en nada crece la personalidad del hombre, el valor de un hombre no se mide por su saber sino por su querer” (Zuretti, 1988, pág. 259); ya que la pedagogía se fundamenta en el ser Humano.

\section{REFERENTES CONCEPTUALES:}

DERECHOS HUMANOS:

Existen independientemente del conocimiento de ellos.

Los Derechos Humanos son todas aquellas prerrogativas que el Estado y la sociedad deben a toda persona por el solo hecho de ser un ser humano:

Pueden definirse como los derechos inherentes a nuestra naturaleza, sin los que no podemos vivir como seres humanos. Los derechos humanos y las libertades fundamentales nos permiten desarrollarnos plenamente y hacer uso de nuestras cualidades humanas [...] la ausencia de ellos no solo constituye una tragedia individual y personal sino crea las condiciones de la inestabilidad social y política donde germinan la violencia y los conflictos que se producen entre las sociedades y las naciones y dentro de éstas” (Naciones Unidas, 2004, pág. 9).

Los Derechos Humanos son reglas mínimas que regulan la convivencia, los acuerdos donde nos comprometemos a cumplir unos compromisos, siempre y cuando éstos se rijan por normas constitucionales y no vayan en contravía de la Dignidad Humana; son un "conjunto de ideas, facultades y normas jurídicas, morales y políticas que, gracias a las luchas sociales, en cada momento histórico concretan las necesidades básicas de la persona, la sociedad, el Estado y la comunidad internacional” (Rivas, 2009, pág. 53), por 
esto el término de derecho lo utilizamos para reclamar algo justo, como es el caso del derecho a la educación gratuita, el derecho a participar en normas que nos afecten como pertenecientes a un grupo social, el derecho es protegido por la ley y por ello podemos exigir su cumplimiento.

Todas las normas y disposiciones institucionales le permiten a la persona reclamar lo que necesita para vivir de manera digna y para cumplir con los fines propios de la vida en comunidad, Los derechos humanos son demandas, sustentadas en la dignidad humana, reconocidas por la comunidad internacional, que han logrado o aspiran a lograr la protección del ordenamiento jurídico y que por esto se convierten en diques frente a los desmanes del poder. (Defensoria del Pueblo, 2001, pág. 25).

\section{EDUCACIÓN EN DERECHOS HUMANOS:}

"Los derechos humanos deben emerger como reglas de juego en la vida cotidiana, cuerpo legal, discurso y práctica social; se constituyen en principios rectores para la configuración y funcionamiento de los diferentes grupos sociales y como reguladores de las relaciones entre éstos”. (Defensoria del Pueblo, 2009, pág. 66)

La educación en derechos humanos otorga herramientas a los diferentes grupos sociales para generar una nueva cultura de organización, de representación mental de las prácticas políticas y de los sujetos que las realizan, para convocar a una participación con poder de decisión; la educación en derechos humanos se ha ido incorporando a la educación como tema transversal y constituye un valor para la educación, para la democracia y la formación de ciudadanía. 
Está delimitada por el contenido normativo del Derecho a la Educación, como son los tratados y acuerdos e instrumentos internacionales y las normas constitucionales que hacen parte del bloque de constitucionalidad ${ }^{15}$, ya que en muchos casos al compartir la cátedra de Derechos Humanos la delimitamos a la constitución y a normas internas ${ }^{16}$, teniendo presente que debe ser coherente a que "la base de la enseñanza de los Derechos Humanos se encuentra en la vida diaria de la escuela” (Rayo, 1993, pág. 35), en la educabilidad del ser humano que potencien la convivencia, la redimensión de lo cultural y especialmente del mismo conocimiento de los Derechos Humanos.

La educación para los derechos humanos está orientada "al desarrollo de competencias ciudadanas y básicas en función de la formación de sujetos activos de derechos, como una razón fundamental del quehacer de la escuela." (Defensoria del Pueblo, 2009, pág. 42), y frente a numerosos desafíos, establece herramientas indispensables para que la sociedad pueda progresar hacia la paz y la democracia.

"El país no cuenta con un sistema estructurado de formación de agentes educativos que integre de manera sistemática la reflexión pedagógica y didáctica sobre la EDH” (Defensoria del Pueblo, 2009, pág. 59), para la inclusión de programas a nivel nacional es importante crear una red de docentes que compartan experiencias significativas en formación de los Derechos Humanos al interior de cada institución.

\footnotetext{
15 El bloque de constitucionalidad es entendido por aquellas normas explícitas incorporadas en la constitución política, los acuerdos y tratados internacionales y la jurisprudencia emanada por la corte desde sus fallos, por ejemplo: en el caso de despenalización del aborto, una mujer puede tomar esta opción si se encuentra dentro de los tres casos de despenalización, además debe ser asistida por el servicio médico estatal.

${ }^{16}$ Como son los manuales de convivencia
} 
La educación, "Es un derecho humano intrínseco y un medio indispensable de realizar otros derechos humanos" (Oficina del Alto Comisionado de las Naciones Unidas para los Derechos Humanos, 2003, pág. 251); no debe centrarse sólo en la transmisión de conocimientos específicos de cada materia, debe ser el principio de un conocimiento general para iniciar un proyecto de vida congruente a nuestra realidad, que tenga sentido para el individuo y para la sociedad.

Esto busca constituirse en un factor decisivo en la democratización y la formación para la ciudadanía, siendo uno de los retos desde el Ministerio de Educación Nacional, posicionando programas transversales como son las competencias ciudadanas definidas por esta entidad.

La educación en Derechos Humanos debe fortalecer las habilidades de los estudiantes para que puedan identificar, analizar, mediar, conciliar y ofrecer soluciones a los conflictos que sean acordes con la ética de los Derechos Humanos.

\section{A MANERA DE CONCLUSIÓN:}

La educación, especialmente la educación de los Derechos Humanos, educan al individuo teniendo en cuenta sus necesidades; se deben desarrollar entre los alumnos hábitos comportamentales para una sana convivencia, los contenidos de la enseñanza deben ser totales, no direccionados intencionalmente para abusar del poder, "a partir de una actitud arrogante del profesor hacia la supuesta "ignorancia" del estudiante" (Restrepo, 2003, pág. 34);

Para lograr una educación de calidad se requiere de un cambio en el proceso escolar, una transformación de la práctica de la enseñanza, del aprendizaje en relación con la 
cultura, la ciencia y el saber, en el cuál se generen nuevas formas de organizar la enseñanza y de aprender;

Es obligación del Estado velar por la progresividad de los Derechos Humanos, mejorando la inversión en la profesionalización docente, especialmente en el conocimiento en educación en Derechos Humanos;

Los programas de estudio profesional deben tener inmersa la educación en Derechos Humanos como cátedra obligatoria en todos los pregrados;

Los instrumentos comportamentales, como el Manual de Convivencia deben ser elaborados como lo dice la Ley de Educación y las normas constitucionales, por la comunidad educativa incluyendo a los niños, niñas y jóvenes, que a su vez son direccionados por los docentes;

Los garantes de los Derechos Humanos son el Estado y los particulares que cumplan funciones estatales, no los niños, las niñas y los jóvenes, quienes necesitan conocimientos para que en un futuro sean ellos quienes en diferentes ocasiones sustenten el respeto de los Derechos Humanos, para hacer efectiva la eliminación de toda forma de discriminación;

La educación en Derechos Humanos debe fortalecer las habilidades de los estudiantes para que puedan identificar, analizar, mediar, conciliar y ofrecer soluciones a los conflictos que sean acordes con la ética de los Derechos Humanos.

Los concursos docentes deben respetar la profesionalización docente; en este momento en el que pueden ingresar otros profesionales, que si bien como se especificó anteriormente "son buenos profesionales", es importante la exigencia de formación 
pedagógica y, especialmente, el conocimiento en educación en Derechos Humanos ya que son los educandos los que se benefician de las buenas prácticas al interior del aula;

Tanto como los docentes, los directivos y administradores deben conocer las directrices nacionales e internacionales de los derechos humanos para evitar la vulneración de estos y multiplicar las prácticas dañinas al interior de las instituciones educativas.

La educación en derechos humanos no es simplemente enunciados teóricos transmitidos en enseñanza tradicional direccionada, sino conocimientos precisos que como docentes los transmitimos en valores y vivencias en todo el ámbito escolar.

\section{Bibliografía}

Tutela 779 de 2011, Derecho a la educación, Tratamiento constitucional con doble connotación como derecho y como servicio (Magistrado Jorge Ignacio Pretelt Chaljub, 20 de Octubre de 2011)

Tutela 618 de 1998, Reglamento Educativo (Magistrado José Gregorio Hernandez, 29 de Octubre de 1998).

Tutela Derecho a la educación, Sentencia T-331/98 (Magistrado Dr Fabio Moron Diaz, 3 de julio de 1998).

Tutela 695 de 1999, Reiteración de Jurisprudencia, T-220424 (Magistrado Carlos Gabiria Diaz 16 de Septiembre de 1999).

Informe de la Alta Comisionada de las Naciones Unidas para los Derechos, E/CN.4/2006//009 (Naciones Unidas, Consejo Económico y Social 20 de Enero de 2006).

Tutela 345 de 2008, T-1811834 (Magistrado Jaime Araujo Renteria 17 de Abril de 2008).

Alcaldia Mayor de Bogotá, Secretaria de Educación. (2005). Catedra de derehos Humanos. Bogotá:

Alcaldia Mayor de Bogotá, Secretaria de Gobierno. (2007). El Derecho a Vivir los Derechos en la Bogotá Humana y Moderna. Bogotá: Imprenta Nacional de Colombia. 
Deas, M. (1 de enero de 1990). publicación digital en la pagina wed de la Biblioteca Luis Ángel Arango del Banco de la Republica. Recuperado el 25 de 03 de 2011, de tipos y costumbres de la nueva granada: http://www.lablaa.org/blaavirtual/credencial/enero 1990/enero1.htm

Defensoria del Pueblo. (2001). Que son los Derechos Humanos. Bogotá: Imprenta Nacional de Colombia.

Defensoria del Pueblo. (23 de Noviembre de 2009). PLANED, Plan Nacional de Educación de Derechos Humanos. Recuperado el 16 de febrero de 2012, de www.defensoria.org.co: http://www.defensoria.org.co/red/anexos/pdf/08/planedh_08.pdf

Departamento Nacional de Planeación. (Agosto de 1987). Plan de Economía Social. Recuperado el 26 de Abril de 2012, de http://www.dnp.gov.co/PND/PlanesdeDesarrolloanteriores.aspx: http://www.dnp.gov.co/Portals/0/archivos/documentos/GCRP/PND/Barco_Program as_Sector_Dllo_Social.pdf

Helg, A. (1987). La educación en Colombia: 1918-1957. Bogotá: Plaza \& Janes.

Huertas D., O., Cáceres T., V., Nathalia, C. T., \& Gómez C., W. (2005). Convención Americana de Derechos Humanos. Bogotá: Universidad Autónoma de Colombia.

Instituto Interamericano del Niño, la Niña y Adolescentes. (20 de marzo de 2012). Presentación del informe de gestión 2011 ante la IIN, ante la Comisión General del Consejo Permanente de la OEA - Intervenciones de los Estados Miembros. Recuperado el 3 de abril de 2012, de www.iin.oea.org: http://www.iin.oea.org/IIN2011/novedades_detalle.shtml?idioma=E\&id=114

Magendzo, A. (2005). Educación en Derechos Humanos. Bogotá: Cooperativa Editorial Magisterio.

Manacorda, M. A. (1987). Historia de la Educación 2, del 1500 a nuestros días. Maxico D.F.: Siglo XXl editore, S.A. de C.V.

Ministerio de educación. (27 de julio de 2010). Que es el Eduderechos. Recuperado el 24 de abril de 2012, de www.mineducación.gov.co: http://www.mineducación.gov.co/1621/article-241007.html

Ministerio de Educación. (18 de enero de 2012). La educación es una parte integral de los Derechos Humanos. Recuperado el 27 de abril de 2012, de www.mineducacion.gov.co: http://www.mineducacion.gov.co/cvn/1665/w3-article294641.html 
Ministerio de Educación Nacional. (5 de Agosto de 1994). Dectreto 1860 de 1994.

Recuperado el 16 de Febrero de 2012, de www.mineducacion.gov.co: http://www.mineducacion.gov.co/1621/articles-104182_archivo_pdf.pdf

Ministerio de Educación Nacional. (8 de febrero de 1994). Ley 115 de 1994. Recuperado el 15 de abril de 2012, de www.mineducacion.gov.co:

http://menweb.mineducacion.gov.co/normas/concordadas/Decreto115.htm

Ministerio de Educación Nacional. (2003). Ley General de Educación, Ley 115. Bogotá: Editorial Union Ltda.

Ministerio de Educación Nacional. (Marzo de 2006). Fondos de Servicios Educativos. Recuperado el 26 de febrero de 2012, de www.mineducacion.gov.co: http://www.mineducacion.gov.co/cvn/1665/articles-114277_archivo_ppt6.pdf

Ministerio de Educación Nacional. (diciembre de 2008). Plan Decenal 2006, 2015. Recuperado el 2012 de abril de 20, de www.gobierno en linea.gov.co: http://programa.gobiernoenlinea.gov.co/apc-aafiles/5854534aee4eee4102f0bd5ca294791f/GEL_ME_EstudioCaso_MinEducacion _PlanDecenalEducacion2008.pdf

Mockus, A. (1997). Las fronteras de la escuela. Bogotá: Cooperativa Editorial Magisterio.

Naciones Unidas . (2004). La Enseñanza de los Derechos Humanos, actividades practicas para escuelas primaria y secundarias. Nueva York y Ginebra: Publicación de las Naciones Unidas.

Naciones Unidas. (21 de febrero de 2006). Asamblea General, Sexagésimo periodo de sesiones. Naciones Unidas.

Oficina del Alto Comisionado de las Naciones Unidas para los Derechos Humanos. (2003). Compilación de Jurisprudencia y Doctrina Nacional e Internacional, Volumen ll. Bogotá: Impresaión Nuevas Ediciones Ltda.

Oficina en Colombia del Alto Comisionado de las Naciones para los Derehos Humanos. (2003). Compilación de Instumentos Internacionales. Bogotá: Impresión Servigraphic Ltda.

Oficina en Colombia del Alto Comisionado de las Naciones Unidas para los Derechos Humanos. (2003). Compilación de jurisprudencia y doctrina nacional e internacional . bogota: Nuevas Ediciones Ltda.

Oliveira, I. A. (2002). Paulo Freire y la Formación de Educadores. mexico: siglo xxi editores. 
Otero, H. (diciembre de 2011). Aty ñomonguetara de niñas, niños y adolecentes del sur. Recuperado el 28 de marzo de 2012, de http//www.cdia.org.py/gfx/publicaciones/Aty\%20\%C3\%91omonguetara\%20de\%lo s\%20NNA\%20del\%20 Sur.pdf

Planeación, C. N. (1961). Plan General de Desarrollo Económico y Social 1961, 1970. Recuperado el 26 de 04 de 2012, de http://www.dnp.gov.co/PND/PlanesdeDesarrolloanteriores.aspx: http://www.dnp.gov.co/Portals/0/archivos/documentos/GCRP/PND/Lleras3_Econo _Colombiana_Ultimo_Decenio.pdf

Presidencia de La Republica. (2011). Constityución Política de Colombia. Bogotá: Editorial Cupido.

Rayo, J. T. (1993). Educar en los Derechos Humanos. Madrid: Editorial CCS.

Restrepo, G. (2003). C iencias Sociales: Saberes Mediadores. Bogotá: Cooperativa Editorial Magisterio.

Ricardo Garcia Duarte, R. (2004). Lo Publico: Del Paradigma Clásico A la Crisis Moderna. Bogotá: Fondo de Publicaciones, Universidad Distrital.

Rivas, H. O. (2009). Cartilla de los Derechos Humanos. Bogotá: Editorial Temis S.A.

Universidad Distrital Francisco José de Caldas. (2003). Conjeturas, Proyecto curricular de ciencias sociales. Bogotá: Sección de publicaciones, Universidad Distrital Francisco José de Caldas .

Zuretti, J. C. (1988). Breve Historia de la Educación. Argentina: Editorial Claridad S.A. 